\title{
Sistem Informasi Pendaftaran Pernikahan Berbasis Web Pada Kantor Urusan Agama Kecamatan Banyumas
}

\author{
${ }^{1)}$ Chandra Kesuma, ${ }^{2)}$ Yustina Meisella Kristania, ${ }^{3)}$ Fatimah Isnaeni \\ ${ }^{1)}$ Manajemen Informatika, AMIK BSI Pontianak \\ chandra.cka@bsi.ac.id \\ ${ }^{2)}$ Sistem Informasi, STMIK Nusa Mandiri Jakarta \\ yustina.yms@nusamandiri.ac.id \\ ${ }^{3)}$ Sistem Informasi,Universitas BSI Bandung \\ fatimahisnaeni10@gmail.com
}

\begin{abstract}
The use of internet for the needs of online registration has begun to develop in Indonesia Archipelago. People can access information and register marriage more easily and quickly through the internet without having to visit KUA first. Through the website KUA officers can easily view the marriage registration data. Registration of marriage to KUA Banyumas Subdistrict still using manual registration method by way of bride to visit KUA Banyumas Sub-district then do face-to-face registration with KUA officer so that less effective and efficient time. The registration information system through the internet or online is a good approach to improving accessibility to the community. The research method used is quantitative and qualitative. The Office of Religious Affairs of Banyumas Sub-district is an Office under the Ministry of Religious Affairs that conducts marriage services for the community around Banyumas Sub-district and provides information for the ease of the community in order to access more effectively and efficiently for prospective marriage applicants.
\end{abstract}

\section{Keywords: Information System, Online Registration System, KUA District Banyumas}

Abstrak - Penggunaan internet untuk kebutuhan pendaftaran online sudah mulai berkembang di Nusantara Indonesia. Masyarakat bisa mengakses informasi dan melakukan pendaftaran pernikahan dengan lebih mudah dan cepat melalui internet tanpa harus berkunjung ke KUA terlebih dahulu. Melalui website petugas KUA bisa dengan mudah melihat data pendaftar pernikahan. Pendaftaran pernikahan pada KUA Kecamatan Banyumas masih menggunakan metode pendaftaran manual yaitu dengan cara calon pengantin mendatangi KUA Kecamatan Banyumas lalu melakukan pendaftaran secara tatap muka dengan petugas KUA sehingga kurang efektif dan efisien dalam manajemen waktu. Sistem informasi pendaftaran melalui internet atau online merupakan suatu pendekatan yang baik terhadap peningkatan kemudahan akses untuk masyarakat. Metode penelitian yang digunakan adalah kuantitatif dan kualitatif. Kantor Urusan Agama Kecamatan Banyumas merupakan sebuah Kantor dibawah Kementerian Agama Republik Indonesia yang secara langsung bertugas melakukan pelayanan pernikahan untuk masyarakat sekitar Kecamatan Banyumas dan memberikan informasi kepada masyarakat agar dapat mengakses dengan lebih efektif dan efisien bagi calon pendaftar pernikahan.

\section{Kata Kunci : Sistem Informasi, Sistem Pendaftaran online, KUA Kecamatan Banyumas}

\section{A. PENDAHULUAN}

Pengetahuan dan teknologi serta informasi di era Masyarakat mengalami perkembangan yang sangat pesat memberikan dampak yang luar biasa dalam pola kehidupan masyarakat. Teknologi informasi telah membuat kehidupan masyarakat yang dinamis dan cepat. Dengan adanya kemudahan-kemudahan yang diberikan, mendorong masyarakat untuk memanfaatkan teknologi informasi dan komunikasi guna membantu dalam aktifitas setiap harinya

Teknologi informasi yang paling populer sekarang ini adalah internet, internet merupakan salah satu alat komunikasi penyebar informasi yang sangat cepat dan murah. Dengan adanya internet memberi kemudahan manusia dalam mengakses informasi serta melakukan berbagai hal, tidak terkecuali dalam penyebaran informasi agar lebih efisien. Melalui website pendaftaran ini, calon pengantin bisa dengan mudah melakukan pendaftaran pernikahan lebih cepat tanpa melakukan face to face dengan petugas.

Keuntungan yang diperoleh melalui website pendaftaran pernikahan berbasis website ini adalah untuk memudahkan calon pengantin tanpa harus datang dan mengantri pada kantor urusan agama. Media pendaftaran pada KUA Kecamatan Banyumas masih menggunakan metode tradisional di mana calon pengantin mengunjungi kantor KUA untuk pendaftaran pernikahan dan akan mendapatkan informasi lebih detail tentang syarat ketentuan akad 
nikah. Salah satu cara untuk pemecahan masalah tersebut yaitu dengan metode sistem informasi pendaftaran pernikahan berbasis web pada kantor urusan agama Kecamatan Banyumas sebagai media yang akan memudahkan calon pengantin untuk mendaftarkan diri. Diharapkan dengan metode ini dapat meningkatkan mutu dan memudahkan masyarakat yang akan mendaftarkan diri untuk menikah.

Berdasarkan uraian di atas, menujukan bahwa masalah metode pendaftaran pada kantor urusan agama kecamatan Banyumas masih menggunakan metode tradisional sehingga dalam pelayanan masyarakat kurang optimal. Adapun judul yang dikemukakan dalam Laporan Skripsi ini adalah "SISTEM INFORMASI PENDAFTARAN PERNIKAHAN BERBASIS WEB PADA KANTOR URUSAN AGAMA KECAMATAN BANYUMAS".

\section{B. TINJAUAN PUSTAKA}

1. Sistem Informasi

a) Sistem

Menurut Dermawan, dkk (2013:4) "Sistem kumpulan atau grup dari bagian atau komponen apapun baik fisik apapunbaik fisik yang saling berhubungan satu sama lain dan bekerjasama secara harmonis untuk mencapai satu tujuan dan mengolah data menjadi informasi yang berguna".

\section{b) Informasi}

Menurut Dermawan, dkk (2013:2) "Informasi merupakan hasil dari pengolahan data, akan tetapi tidak semua hasil dari pengolahan tersebut bisa menjadi informasi, hasil pengolahan data yang tidak memberikan makna atau arti serta tidak bermanfaat bagi seseorang". Suatu sistem tidak akan berjalan dengan baik tanpa adanya informasi. Informasi juga disebut sebagai data yang diproses atau data yang memiliki arti. Data merupakan sumber informasi yang menggambarkan suatu kejadian yang terjadi pada saat tertentu, yang kemudian data tersebut diolah dan digunakan untuk menjadi input pada suatu sistem.

c) Sistem Informasi

Menurut Dermawan, dkk (2013:13) "Sistem Informasi merupakan kumpulan sub-subsistem yang saling berhubungan satu sama lain, yang bekerja secara harmonis untuk mencapai satu tujuan, yaitu mengelola data menjadi informasi yang berguna".

2. Pendaftaran

Menurut Kamus Besar Bahasa Indonesia (2016) kata "Pendaftar" berarti proses, cara perbuatan mendaftar atau mendaftarkan, pencatatan nama, alamat, dan sebagainya dalam daftar. Dapat disimpulkan bahwa pendaftaran adalah proses kegiatan yang dilakukan oleh seseorang untuk menjadi salah satu dari bagian lingkup yang didaftar.

\section{Pernikahan}

Menurut Almutaqqin (2016:55) "Sistem informasi pernikahan adalah suatu kumpulan informasi yang mendukung pemenuhan kebutuhan suatu organisasi, yang bertanggung jawab untuk menyediakan informasi pernikahan dalam suatu kesatuan proses yang saling berkaitan antara petugas KUA dan masyarakat, yang bersama-sama bertujuan untuk perkembangan pelayanan KUA terhadap masyarakat".

\section{Website}

Menurut Ahmadi dan Hermawan (2013:69) menerangkan bahwa "WorldWide Web, lebih terkenal disingkat sebagai WWW adalah suatu ruang informasi yang dipakai oleh pengenal global yang disebut Pengidentifikasi Sumber Seragam untuk mengenal pasti sumber daya berguna". WWW sering dianggap sama dengan internet secara keseluruhan, walaupun sebenarnya ia hanyalah bagian dari internet.

Menurut Abdulloh (2016:1) "website atau disingkat web dapat diartikan sekumpulan halaman yang terdiri atas beberapa laman yang berisi informasi dalam bentuk data digital, baik berupa teks, gambar, video, audio, dan animasi lainnya yang disediakan melalui jalur koneksi internet".

\section{a. Web browser}

Menurut Abdulloh (2016:5) "web browser digunakan untuk menampilkan hasil website yang telah dibuat". Web browser yang paling sering digunakan, di antaranya Mozilla Firefox, Google Chrome, Internet Explorer, Opera, dan Safari.

b. Web Server

Pengguna internet idealnya tidak asing dengan web server. Ketika seorang pengguna internet membuka atau mengakses alamat website tertentu melalui browser secara otomatis pengguna sedang terhubung atau menggunakan web server.

c. Web Hosting

Menurut Ahmadi dan Hermawan (2013:53) "Web Hosting adalah salah satu bentuk layanan jasa penyewaan tempat di internet yang memungkinan perorangan ataupun organisasi menampilkan layanan jasa atau produknya di web atau situs internet". Tempat disini dapat juga diartikan sebagai tempat penyimpanan data berupa megabytes (mb) hingga terabytes (tb) yang memiliki koneksi ke internet, sehingga data tersebut dapat direquest atau diakses oleh user dari semua tempat secara simultan. Inilah yang 
menyebabkan sebuah website dapat diakses bersamaan dalam satu waktu oleh multiuser.

d. Domain

Menurut Prasetyo (2015:22) "Domain adalah alamat unik dan berguna untuk mencari alamat sebuah website". Dengan adanya domain maka akan mempermudah penyebutan atau pemanggilan data atau informasi pada sebuah server.

5. Bahasa Pemrograman

Bahasa pemrograman merupakan sarana penghubung antara yang diharapkan pembuat dengan program itu sendiri menggunakan bahasa yang dimengerti oleh sistem. Untuk membuat website Pendaftaran Pernikahan Berbasis web pada KUA Kecamatan Banyumas penulis menggunakan Beberapa Bahasa Pemrograman yang dikombinasikan untuk menerapkan logika ke dalam sistem yang akan dibuat, beberapa Bahasa Pemrograman yang digunakan antara lain:

a. HTML

Menurut Abdulloh (2016:2) "HTML singkatan dari Hyper Text Markup Language, yaitu skrip yang berupa tag-tag untuk membuat dan mengatur struktur website". Beberapa tugas utama HTML dalam membangun website di antaranya sebagai berikut: Menentukan layout website, memformat teks dasar, seperti pengaturan paragraf dan format font, membuat list dan tabel, menyisipkan gambar, video, dan audio, membuat link, membuat formulir.

b. PHP

Digunakanuntuk membuat tampilan web mejadi lebih dinamis, dengan PHP dapat menampilkan atau menjalankan beberapa file dengan cara di include atau require. Menurut Wardana (2016:26) "MySQL merupakan program aplikasi untuk membuat suatu DBMS (DataBase Management System) yang berbasis SQL (structured Query Language)". c. CSS

Menurut Abdulloh (2016:2) "CSS singkatan dari Cascading Style Sheets, yaitu skrip yang digunakan untuk mengatur desain website". Fungsi CSS adalah memberikan pengaturan yang lebih lengkap agar struktur website yang dibuat dengan HTML terlihat lebih rapi dan elegan.

\section{d. Javascript}

Website yang ramah dengan pengunjung juga menggunakan animasi sebagai faktor untuk menambah tingkat keindahan dan kenyamanan pengunjung saat menjelajah di website. Javascript juga bisa digunakan untuk mengatur hal-hal yang tidak bisa dilakukan HTML, PHP ataupun CSS, misalkan membuat kotak dialog.

6. Aplikasi Perangkat Lunak a. Software

Menurut Pawirosumarto (2013:39) menerangkan bahwa "Software (Perangkat Lunak) adalah program komputer yang berfungsi sebagai sarana interaksi antara pengguna dan perangkat keras". Berikut ini beberapa aplikasi yang Penulis gunakan:

1. Atom

Atom Versi 1.15.0 adalah sebuah text editor yang memiliki lisensi open source yang tersedia untuk platform OS $\mathrm{X}$, Linux dan Windows. (belajar ngoding, 2015, belajarngoding.com/reviewtentang-atom-text-editor/, 19 Mei 2017).

2. XAMPP

XAMPP merupakan program paket PHP dan MySQL berbasis open sourceyang saat ini merupakan andalan para programmer PHP dalam melakukan testing hasil programnya (Yudhanto dan Purbaya dalam Supriyanta dan Nisa, 2015). Kelebihan dari XAMPP antara lain XAMPP berjalan pada background sehingga bisa tidak mengganggu aktivitas lainnya, Service tetap berjalan jika sistem di log off karena jika sebagai server, pengaturan lalu lintas data harus tetap berjalan, Dapat membatasi kewenangan tiap akun yang mengakses jadi keamanan lebih terjamin.

3. Coreldraw

Menurut Rahadi, et al (2016:45) "Corel Draw adalah sebuah program komputer yang melakukan editing pada garis vektor". Program ini dibuat oleh Corel, sebuah perusahaan software yang berkantor pusat di Ottawa, Kanada.

Coreldraw memiliki kegunaan untuk mengolah gambar, oleh karena itu banyak digunakan pada pekerjaan dalam bidang publikasi atau percetakan ataupun pekerjaan di bidang lain yang membutuhkan proses visualisasi.

Grafik yang halus adalah salah satu faktor untuk membuat tampilan website menjadi lebih indah di pandang, oleh karena itu dibutuhkan aplikasi untuk menambah nilai estetika pada gambar yang digunakan dalam website yang akan dibuat.

\section{b. Framework}

Menurut Wardana (2016:3) "Framework adalah kumpulan perintah atau fungsi dasar yang membentuk aturan-aturan tertentu dan saling berinteraksi satu sama lain sehingga dalam pembuatan aplikasi website kita harus mengikuti aturan dari framework tersebut. Framework yang dimaksud adalah kumpulan dari beberapa fungsi yang di buat oleh orang atau perusahaan fungsinya adalah 
memudahkan pengembang agar terutama mengurangi waktu pembuatan sebuah website. Beberapa framework yang digunakan untuk membuat website KUA Kecamatan Banyumas adalah sebagai berikut:

\section{Boostrap}

Menurut Abdulloh (2016:157) "Bootstrap merupakan salah satu framework CSS yang sangat populer dikalangan pecinta pemrograman website. Dengan menggunakan bootstrap, proses desain website tidak dibuat dari nol, sehingga proses desain website lebih cepat dan mudah".

2. Data Tabel

Menurut Purbadian (2016:29) menyimpulkan bahwa "Data Table adalah sebuah plugin jQuery yang sangat power full. Di samping mudah untuk mengimplementasikannya, plugin jQuery data table sudah terintegrasi dengan search form, pagination, serta jumlah data yang akan ditampilkan".

\section{Basis Data}

Menurut Rosa dan Shalahuddin (2013:43) "Basis data adalah sistem terkomputerisasi yang tujuan utamanya adalah memelihara data yang sudah diolah atau informasi dan membuat informasi tersedia saat dibutuhkan". Pada intinya basis data adalah media untuk menyimpan data agar dapat diakses dengan mudah dan cepat.

a. MySQL

Menurut Padang (2017:40) "MySQL merupakan komponen yang digunakan untuk mengakses atau berkomunikasi dengan database MySQL melalui PHP”. Beberapa manfaat penggunaan MySQL yaitu:Menggunakan Interface/metode object oriented,menggunakan penggunaan prepared statement, mendukung penggunaan multiple statement, mendukung penggunaan transaksi, peningkatan terhadap kemampuan pencarian kesalahan program, mendukung pengembangan dengan server.

b. PHPMyAdmin

Menurut Abdulloh (2016:4) "Phpmyadmin merupakan aplikasi berbasis webyang digunakan untuk membuat database MySQL sebagai tempat untuk menyimpan data-data website".

c. JQuery

Menurut Abdulloh (2016:147) "jQuery merupakan salah satu javascript library, yaitu kumpulan fungsi javascript siap pakai, sehingga mempermudah dan mempercepat kita dalam membuat kode javascript".
8. Model Pengembangan Perangkat Lunak Menurut Rosa Shalahuddin dalam Rahmayu (2016:36) Mengemukakan bahwa "Model air terjun (waterfall) sering juga disebut model sekuensial linier (sequential linier) atau alur hidup klasik (classic cycle)".

9. ERD

Menurut Rosa dan Shalahuddin (2013:53)

"Entity Relationship Diagram (ERD) Merupakan bentuk paling awal dalam melakukan perancangan basis data relasional. Jika menggunakan OODBMS maka perancangan ERD tidak perlu dilakukan".

10.LRS

Menurut Tabrani (2014:35) "LRS adalah Logical Record Structure dibentuk dengan nomor dari tipe record". Beberapa tipe record digambarkan oleh kotak empat persegi panjang dan dengan nama yang unik. Perbedaan LRS dengan E-R diagram adalah nama tipe record berada diluar kotak field tipe record ditempatkan.Aturanaturan dalam melakukan transformasi E-R Diagram ke Logical Relationship Structure menurut Efendi, dkk (2015:7) adalah:

a. Setiap entitas akan diubah ke bentuk sebuah kotak dengan nama entitas berada di dalam kata.

b. Relasi kadang disatukan dengan sebuah kotak bersama entitas kadang dipisah dalam kotak tersendiri.

11.UML

Menurut Sugiarti (2013:30) "UML adalah salah satu bentuk language atau bahasa menurut pencetusnya, UML di definisikan sebagai bahasa visual untuk menjelaskan memberikan spesifikasi, merancang, membuat model dan mendokumentasikan aspek-aspek dari sebuah system".

12.Pengujian Web

Menurut Rosa dan Shalahuddin (2013:275) mendefinisikan "Black Box Testing (pengujian kotak hitam) yaitu menguji perangkat kunak dari segi spesifikasi fungsional tanpa menguji desai dan kode program". Pengujian dimaksud untuk mengatahui apakah fungsi-fungsi, masukan, dan keluaran dari perangkat lunak sesuai dengan spesifikasi yang dibutuhkan.

13.Penelitian Terkait

Dalam pembuatan website ini, penulis mengambil referensi dari jurnal online yaitu:

1. Penelitian yang dilakukan oleh Givo AIMutaqqin tahun 2016 dengan judul "Sistem Informasi Pendaftaran Pernikahan Berbasis 
onlinemenggunakan metode waterfall". Pembuatan website pendaftaran pernikahan pada KUA Kecamatan Mandau-Duri terdapat faktor yang mempengaruhi pembuatan website adalah faktor pelayanan yang kurang cepat serta sering terjadi kesalahan input nama, gelar atau lainnya yang berhubungan dengan calon pendaftar maka dari itu untuk meminimalisir terjadinya kesalahan dengan adanya sistem berbasis online akan memudahkan petugas KUA karena yang menginputkan adalah pendaftar. Pada website ini menggunakan bahasa pemrograman HTML, PHP, CSS, Javascript, Jquery serta menggunakan basis data MYSQL. Terdapat beberapa form dalam pembuatan website ini yaitu form login, form calon istri dan form calon suami. (AlMutaqqin, Givo, 2016).

2. Penelitian yang dilakukan oleh Edi Purnomo dkk dengan judul "Website pendaftaran pernikahan pada KUA Kecamatan Tulakan" Dengan adanya website diharapkan dapat membantu instansi terkait dalam proses input data dan pengarsipan data dari pendaftar pernikahan serta untuk efisiensi waktu tanpa adanya antrian yang membuat masyarakat menunggu. Pada website ini menggunakan bahasa pemrograman HTML, PHP, CSS, Javascript, Jquery serta menggunakan basis data MYSQL. Terdapat beberapa form dalam pembuatan website ini yaitu form login, form calon istri dan form calon suami. (Purnomo, Purnama Eka, Sukadi, 2013) Pengembangan yang akan dilakukan oleh penulis yaitu website Pendaftaran pernikahan berbasis web pada KUA Kecamatan Banyumas akan digunakan oleh calon pendaftar pernikahan secara online dan dapat diakses dimana saja, bukan hanya digunakan oleh instansi terkait dan akan ditambahkan form informasi pelayanan di KUA Kecamatan Banyumas, member akan mendapatkan pesan broadcast melalui e-mail jika telah mendaftar sebagai calon pengantin, menu google map yang bisa diakses oleh pengunjung website.

\section{METODE PENELITIAN}

Metode yang digunakan pada penelitian ini yaitu:

1. Observasi

Pada metode ini dilakukan analisis awal yaitu sebagai bahan untuk melakukan pembuatan perancangan web. Penulis mengamati secara langsung terhadap kegiatan-kegiatan yang dilakukan di KUA Kecamatan Banyumas dalam pendaftaran pernikahan.

\section{Wawancara}

Penulis melakukan tanya jawab langsung kepada Kepala kantor urusan agama Kecamatan Banyumas tentang proses pendaftaran pernikahan.

3. Studi Pustaka

Metode ini dilakukan dengan melakukan pencarian data lewat literatur-literatur yang terkait seperti buku-buku referensi, jurnal, internet dan lain-lain yang berhubungan dengan masalah pokok.

\section{Ruang Lingkup}

Dalam penyusunan skripsi ini, hanya membatasi pada sistem pendaftaran pernikahan pada Kantor Urusan Agama Kecamatan Banyumas Kabupaten Banyumasdimulai dari user diberikan hak akses tertentu, admin diberikan hak akses berupa pengelolaan secara keseluruhan mulai dari pengelolaan input data informasi pendaftaran, masyarakat umum bisa mengakses informasi mengenai pendaftaran pernikahan serta pengumuman yang terdapat dalam website, calon pendaftar bisa melihat informasi mengenai pendaftaran pernikahan serta dapat login menggunakan email dan password serta dapat mengakses formulir yang wajib di isi dan di upload mulai dari $\mathrm{N} 1$ N9 dan N10 jika diperlukan.

\section{E. RANCANGAN SISTEM DAN PROGRAM} USULAN

1. Analisis Kebutuhan Software

\section{a. Tahapan Analisis}

Sistem informasi Pendaftaran Nikah secara online ini bertujuan untuk mempermudah calon pengantin dalam melakukan pendaftaran pernikahan di KUA Kecamatan Banyumas. Berikut ini adalah spesifikasi kebutuhan pada masing-masing pengguna website:

1. Kebutuhan Pengunjung

a. Pengunjung dapat melihat halaman utama web KUA.

b. Pengunjung dapat mendaftar sebagai calon pengantin.

c. Pengunjung dapat melihat google map alamat KUA.

d. Pengunjung dapat membaca profil KUA.

e. Pengunjung dapat melihat petunjuk pendaftaran nikah.

2. Halaman Member

a. Member dapat melengkapi data calon pengantin.

b. Member dapat melengkapi berkas calon pengantin. 
c. Member dapat melihat jadwal untuk akad.

d. Member dapat mencetak bukti jadwal pernikahan.

e. Member dapat melihat petunjuk penggunaan halaman member.

3. Halaman Admin

a. Admin dapat mengecek kelengkapan data formulir calon pengantin

b. Admin dapat mengelola data profil KUA.

c. Admin dapat mengelola data artikel website KUA.

d. Admin dapat mengelola data administrator.

e. Admin dapat melakukan penjadwalan nikah calon pengantin.

f. Admin dapat mengexport data ke dalam Excel, Pdf dan menyalin data.

g. Admin dapat melihat data member.

h. Admin dapat mengubah nama administrator.

b. Use Case Diagram

a) Use case Diagram pengunjung

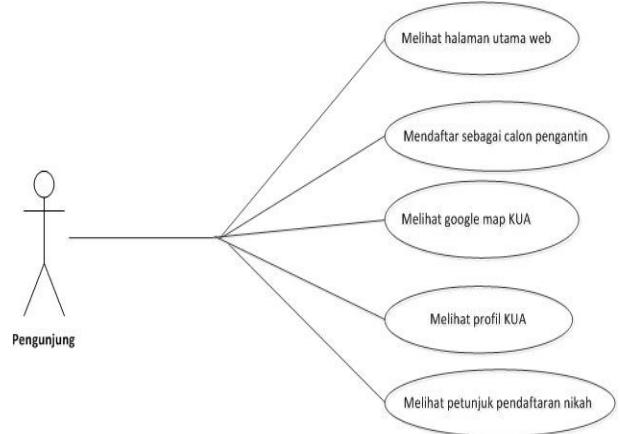

Gambar 1. Use case diagram pengunjung

b) Use case diagram Member

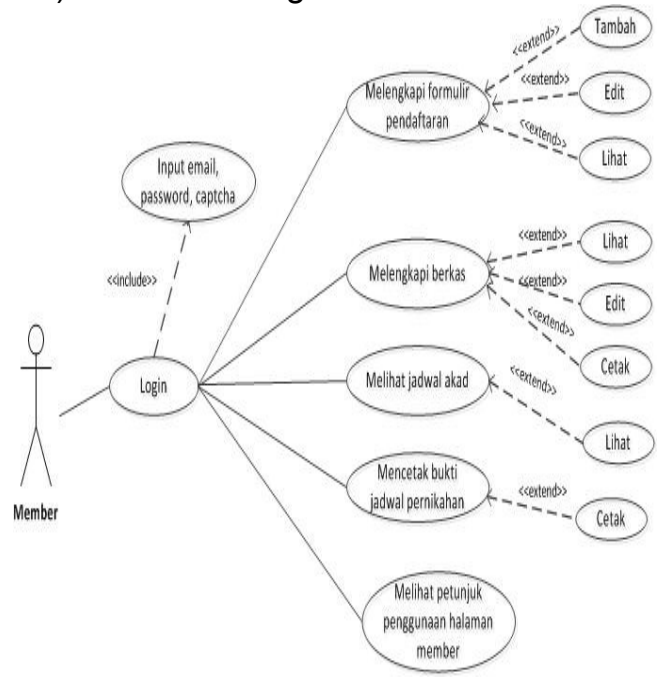

Gambar 2. Use case diagram member c) Use case diagram admin

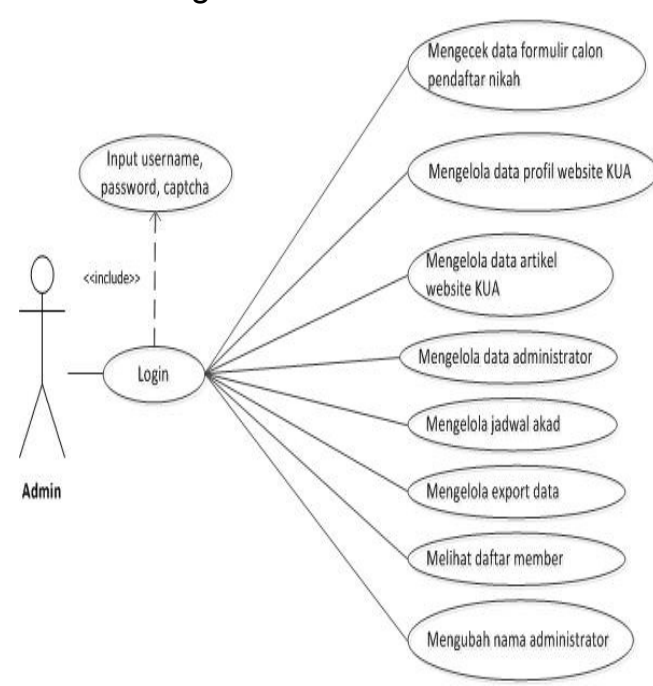

Gambar 3. Use case diagram admin

2. Activity Diagram

a) Activity Diagram Admin mengecek formulir pendaftar nikah

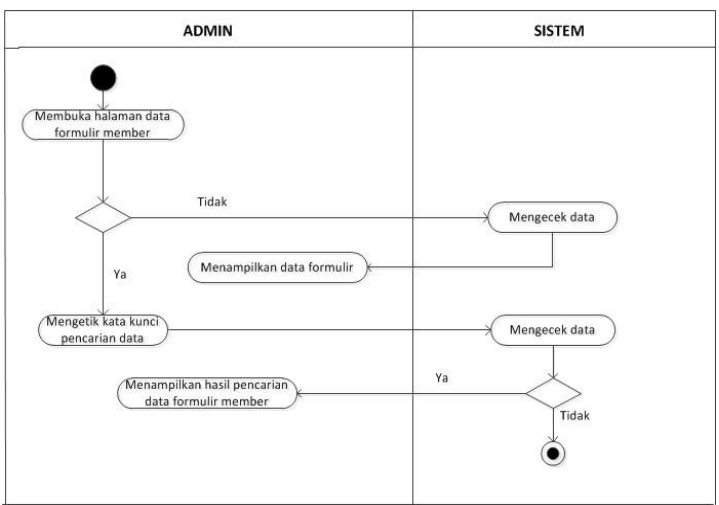

Gambar4.Activity Diagram Admin mengecek formulir pendaftar nikah

b) Activity Diagram Adminmengelola data profil KUA

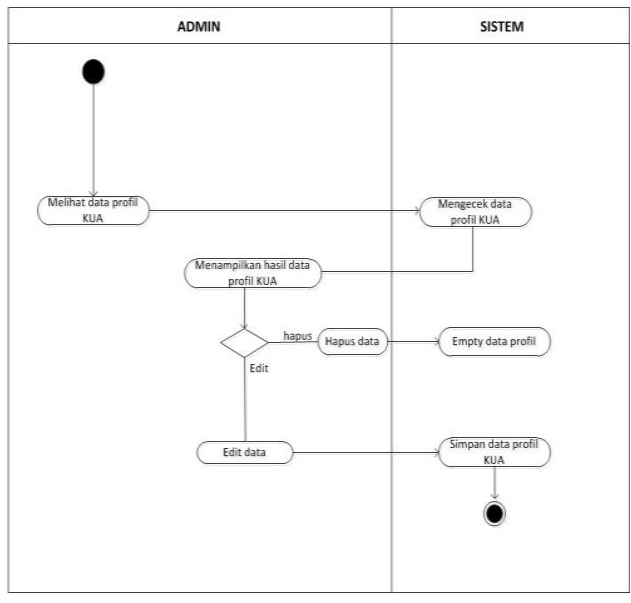

Gambar 5.Activity Diagram Admin mengelola data profil KUA 
c) Activity Diagram data administrator

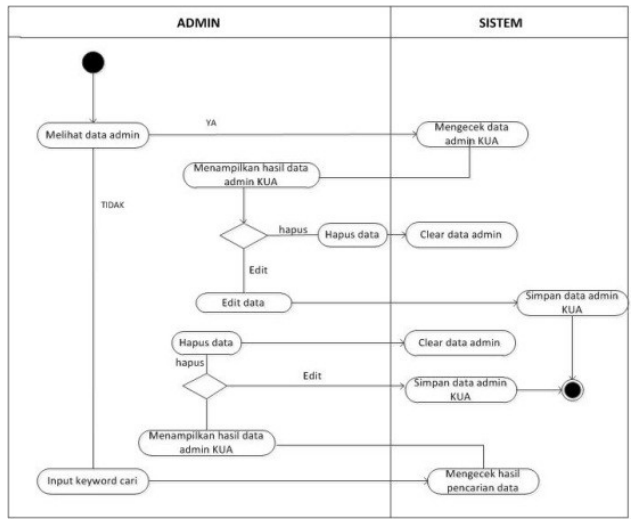

Gambar 6.Activity Diagram Admin mengelola data administrator

d) Activity Diagram Member melengkapi data calon pengantin

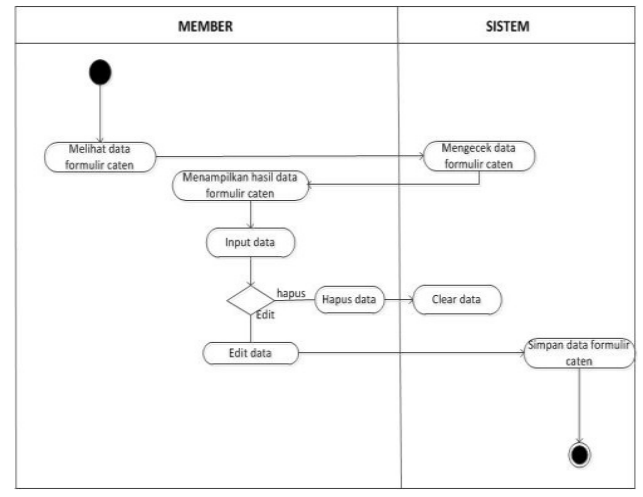

Gambar 7.Activity Diagram Member melengkapi data calon pengantin

e) Activity DiagramMember mencetak bukti pendaftaran

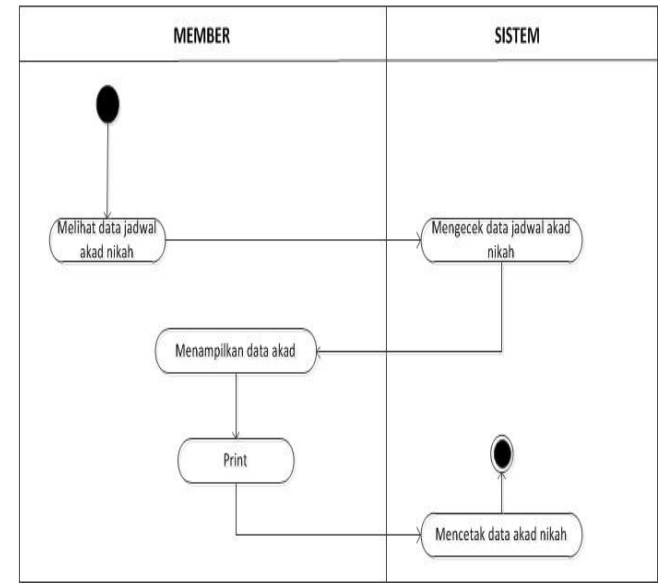

Gambar 8.Activity Diagram Member mencetak bukti pendaftaran f) Activity Diagram pengunjung melihat alur pendaftaran nikah

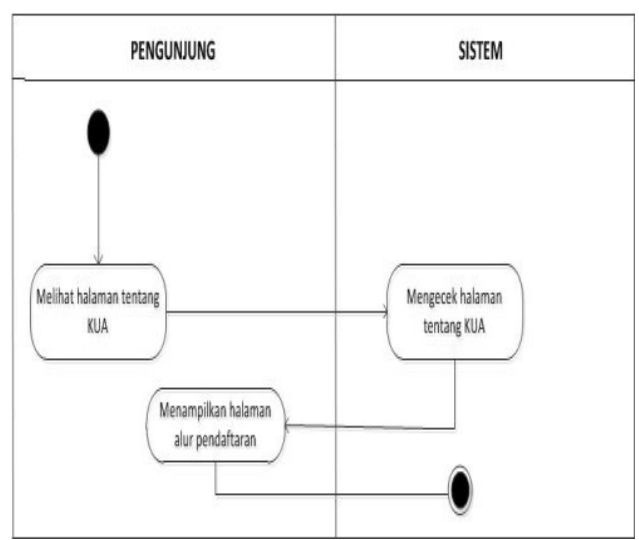

Gambar 9.Activity Diagram Pengunjung melihat alur pendaftaran nikah

g) ERD (Entity Relationship Diagram)

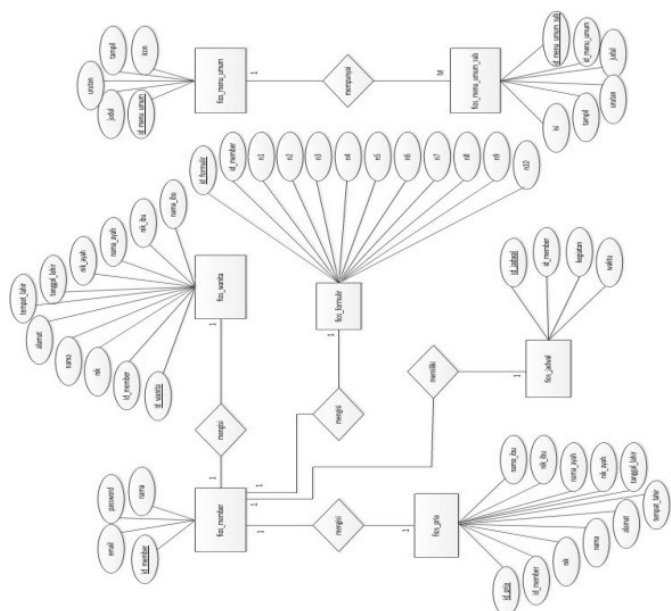

Gambar 10.Entity Relationship Diagram h) LRS (Logical Record Structure)

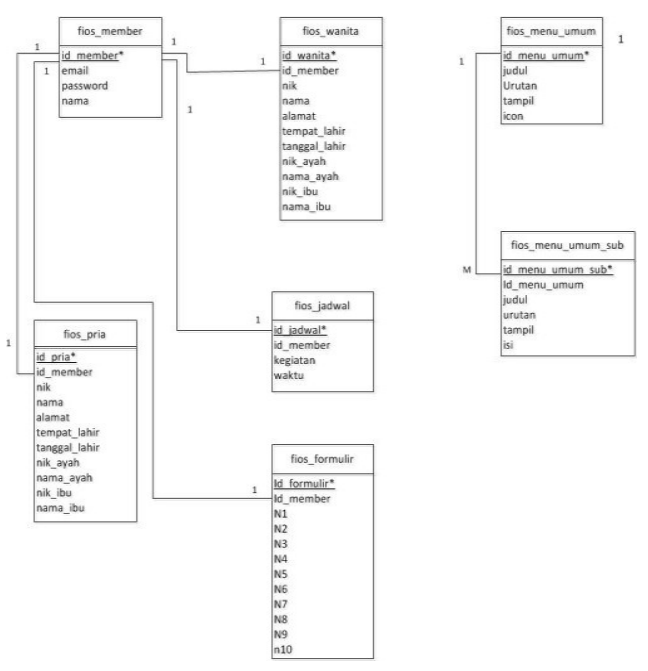

Gambar 11.Logical Record Structure 
3. User Interface

a. Halaman berandapengunjung

Halaman yang pertamakali di lihat oleh pengunjung ketika mengunjungi alamat website KUA Kecamatan Banyumas.

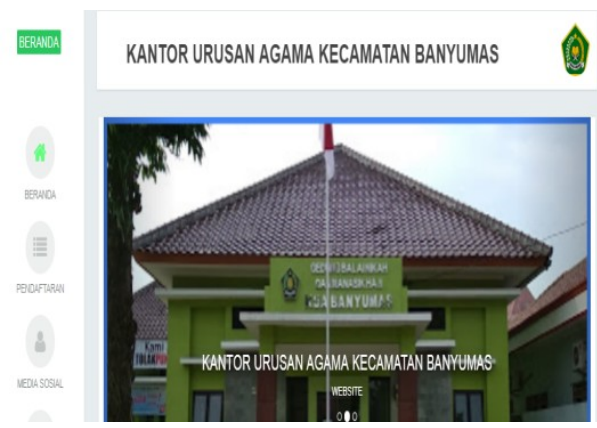

Gambar 12.Halaman Beranda pengunjung

b. Halaman Daftar member

\section{Form Daftar Online Nikah}

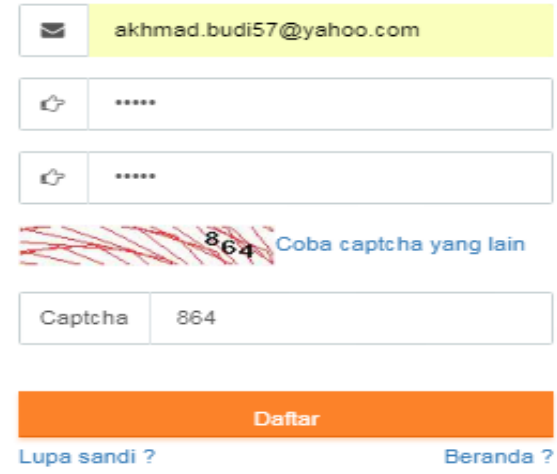

Gambar 13. Halaman Daftar member

c. Halaman login member

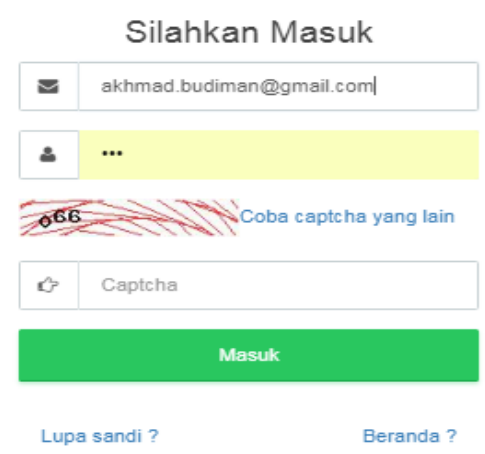

Gambar 14.Halaman Login member

\section{d. Halaman admin edit menu}

Menu Umum

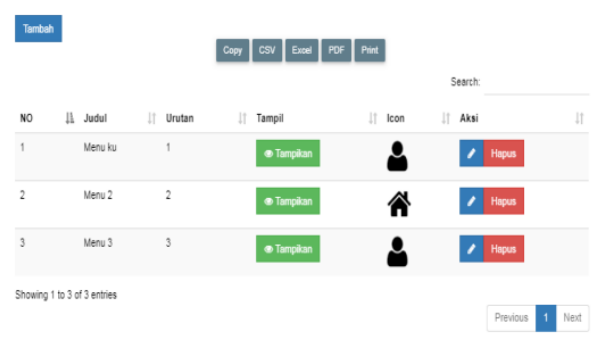

Gambar 16. Halaman adminedit menu e. Halaman admin edit menu layanan

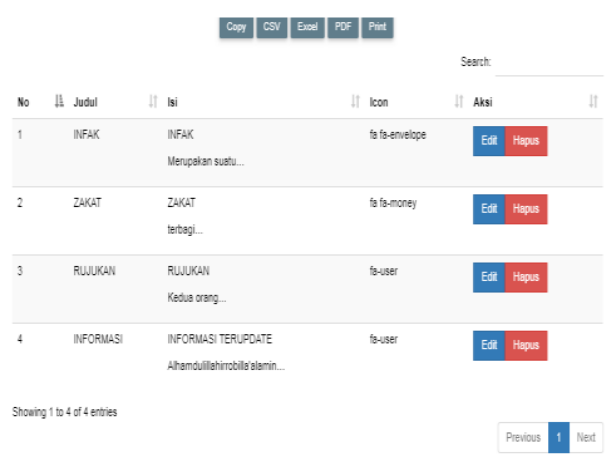

Gambar 17. Halaman admin edit menu layanan

\section{F. KESIMPULAN DAN SARAN}

1. Kesimpulan

Berdasarkan uraian yang telah dibahas pada bab-bab sebelumnya serta hasil rangkaian pengujian terhadap sistem yang dibangun dengan mengambil dan menganalisa data-data yang diperoleh dari website KUA Kecamatan Banyumas. Maka dapat diambil beberapa kesimpulan sebagai berikut:

1. Sebelum adanya sistem pendaftaran pernikahan berbasis web, KUA Kecamatan Banyumas masih melakukan pendaftaran calon pengantin secara manual dengan cara calon pengantin mendatangi KUA Kecamatan Banyumas untuk mendaftar. Sistem pendaftaran pernikahan berbasis web ini dirancang sebagai solusi untuk memudahkan masyarakat agar lebih efektif dan efisien dapat melakukan pendaftaran secara online dimana pun.

2. Pada implementasi sistem pendaftaran pernikahan berbasis web ini dapat dijalankan secaraonline. Dan website ini diharapkan dapat menjadi media untuk menyebarkan informasi tentang ibadah pernikahan ataupun tentang Islam. 


\section{SARAN}

Dari pembahasan sebelumnya, diberikan saran-saran dengan tujuan untuk memaksimalkan penggunaan sistem. Berikut ini adalah saran-saran yang dapat diberikan:

1. Sebelum menerapkan sistem yang baru maka perlu dilakukan pelatihan atau training mengenai website yang akan diterapkan. Dengan pelatihan, tentu admin akan lebih cepat untuk memahami dan siap untuk menggunakan sistem yang baru. Pelatihan sangat penting agar sistem dapat digunakan dengan maksimal.

2. Melakukan backup data secara berkala untuk menanggulangi human error. Hal ini dilakukan karena human error tidak dapat diprediksi. Diharapkan admin rutin membuat cadangan data dari database sistem untuk mencegah hilangnya data pendaftaran.

3. Admin melakukanpengawasan secara rutin setiap hari agar pendaftaran calon pengantin melalui sistem pendaftaran berbasis web ini dapat langsung ditangani dengan cepat dan tepat.

Demikian akhir dari pembahasan mengenai perancangan website"Sistem Informasi Pendaftaran Pernikahan Berbasis Web pada KUA Kecamatan Banyumas".

Menyadari bahwa sistem yang telah dibuat tidak sepenuhnya sempurna dan memiliki banyak kelemahan. Hal tersebut mungkin terjadi karena kesalahan rancangan yang tidak diantisipasi yang dapat menyebabkan gangguan pada sistem. Namun, hal tersebut dapat dicegah dengan backup data secara teratur.

\section{DAFTAR PUSTAKA}

[1] Abdulloh, Rohi. 2016. Web Programing. Jakarta : Elex Media Komputindo.

[2] Ahmadi, Hermawan. 2016. E-Business dan E-Commerce. Yogyakarta : ANDI.

[3] A.S., Rosa dan M. Shalahuddin. 2013. Rekayasa Perangkat Lunak Terstruktur dan Berorientasi Objek. Bandung: Informatika Bandung.

[4] Almuttaqin Givo. 2016. Sistem Informasi Pendaftaran Pernikahan Berbasis Online Menggunakan Metode Waterfall (Study Kasus Kantor Urusan Agama Kecamatan Mandau-Duri). Riau. Volume 2 Agustus 2016. Diambil dari: http:// mandau-duri2608-5764/

[5] Ardiansyah, Doni. 2016. Sistem Informasi Pendaftaran Event dengan
PHP untuk Panduan Skripsi. Cirebon, Jawa Barat: CV. ASFA Solution.

[6] Arinoa, Rian. 2013. Belajar HTML dan CSS. Diambil dari: https://www.ariona.net/.

[7] Dermawan, Deni dan Kunkun Nur Fauzi. 2013. Sistem Informasi Manajemen. Bandung: PT Remaja Rosdakarya.

[8] Frimayasa, Agtovia dkk. 2017. Penerapan Pelayanan Prima Untuk Memenuhi Harapan Masyarakat Terhadap Layanan Publik Pada Kelurahan Makasar, Jakarta Timur. Vol. XVII, No. 2, September 2017:180. pISSN 1411-8629, e-ISSN: 2579-3314. Diambil dari: http://ejournal.bsi.ac.id/ejurnal/index.php Icakrawala/article/view/2428/1794

[9] Herliana, Asti. 2014. Analisa dan Perancangan Sistem Informasi Administrasi Data Pribadi dan Nilai Mahasiswa di Perguruan Tinggi (Studi Kasus Universitas kebangsaan Bandung). Vol. I No. 2 September 2014:83. Diambil dari: http://ejournal.bsi.ac.id/ejurnal/index.php /ii/article/viewFile/41/.

[10] Junianto, Erfian dan YusaPrimaesha. 2015. PerancanganSistem Tracking Invoice Labolatorium pada PT Sucufindo (Persero) Bandung. Vol. II, No. 2, September 2015:442. ISSN : 2355 6579dari:

http://ejournal.bsi.ac.id/ejurnal/index.php /ii/article/download/133/107

[11] Kusniawan, Andi dan Sardiarinto. 2016. Perancangan Website JasaDesain Interior Sebagai Media PemasaranStudiKasus: CV. Focalpoint Interior. Volume 4 Nomor 2 - 2016:1. ISSN:2338-8161.Diambildari: http://ejournal.bsi.ac.id/ejurnal/index.php levolusi/article/download/694/570.

[12] Mulyanto, Dwi Joko dan Uswatun Khasanah. Aplikas Pembayaran DSP dan SPP Sekolah Pada SMK TI Bintra Purwokerto: Volume 6 No1-2018: ISSN: 2338-8161. Diambil dari: http://ejournal.bsi.ac.id/ejurnal/index.php levolusi/article/view/3544.

[13] Padang, Samuel Yacobus. 2017. Membangun Aplikasi TV Kabel dengan 
,Mysql dan Bootstrap. Cirebon. CV Asfa Solution, Software Development, IT dan Publising.

[14] Paryanta dkk. 2017. Sistem Informasi Administrasi Kependudukan Berbasis Web Desa Sawahan. Volume 3 No 2 2017: ISSN : 2461-0690: http://ejournal.bsi.ac.id/ejurnal/index.php lijse/article/view/2980/1929.

[15] Priyanti, Dwi, dkk. 2013. Sistem Informasi Data Penduduk pada Desa Bogoharjo Kecamatan Ngadirojo Kabupaten Pacitan. ISSN: 2302-5700. Diambil dari: http://ijns.org/journal/index.php/ijns/articl e/view/181.

[16] Purbadian, Yenda. 2016. Framework Codelgniter 3. Cirebon : ASFA Solution.

[17] Raharjo, Budi. 2015. Mudah Belajar PHP. Bandung: Informatika Bandung.

[18] Rahman, Su. 2013. Cara Gampang Bikin CMS PHP Tanpa Ngoding. Jakarta: Mediakita.

[19] Rahmayu. 2016. Rancang Bangun Sistem Informasi pada Rumah Sakit dengan Layanan Internet Menggunakan Metode Waterfall. Volume.4.-2016: ISSN:2338-8161. Diambil dari: http://ejournal.bsi.ac.id/ejurnal/index.php levolusi/article/view/699/574.

[20] Rohani, Yoyok. 2015. Rancangan Aplikasi E-learning pada sekolah Menengah Peratama.: Volume 3 No 2September 2015: ISSN: 2338-8145. Diambil dari: http://docshare01.docshare.tips/files/295 08/295086675.pdf.

[21] Sagita Rinandi Awan, Hari Sugiarto. 2016. Penerapan Metode Waterfall Pada Sistem Informasi Penjualan Furniture Berbasis Web. Volume 5 No 4 - Oktober 2016: ISSN : 2302-5700 (Print) - 2354-6654 (Online) Diambil dari:http://ejurnal.net/portal/index.php/iin s/article/view/1346.

[22] Saifudin. 2016. PerancanganSistemlnformasiPondokPe santrenBerbasis Web StudiKasus: Darul AbrorWatumasPurwokerto. Volume 4 Nomor 1 - 2016:32. ISSN: 2338 - 8161. Diambildari: http://ejournal.bsi.ac.id/ejurnal/index.php levolusi/article/download/640/531.

[23] Setiawan, Didik. 2017. Buku Sakti pemrograman web:HTML, CSS, PHP, Mysql dan Javascript.Yogyakarta. Start UP.

[24] Sufryanthi, Yahdi Kusnadi. 2016. Pengaruh Pelayanan Pembuatan E-KTP Terhadap Kepuasan Masyarakat Studi Kasus Di Kecamatan Dramaga Kabupaten Bogor. Vol.XII, No. 1 Maret 2016. ISSN:1978-1946. Diambil dari: http://ejournal.nusamandiri.ac.id/ejurnal/i ndex.php/pilar/article/viewFile/82/78.

[25] Sugiarti, Yuni. 2013. Analisis dan perancangan UML (Unified Modeling Language)Generated VB.6. Yogyakarta. Graha IImu.

[26] Supriyanta dan KhoirunNisa. 2015. Perancangan Website DesaWisataKarangrejasebagai Media Informasi dan Promosi. Vol 3 No 1 Maret 2015:35. ISSN : 2338-9761. Diambildari:

http://ejournal.bsi.ac.id/ejurnal/index.php /Bianglala/article/download/575/466 .

[27] Tabrani, Muhammad. 2014. Implementasi Sisem Informasi Reservasi Penginepan pada Argowisata Gunung Mas Cisarua Bogor.Bianglala Informatika Vol.11.No 1 Maret 2014: 35 ISSN: 2461-0690 1. Diambil dari: http://ejournal.bsi.ac.id/ejurnal/index.php /Bianglala/article/view/559.

[28] Wahana Komputer.2013. Belajar Java Script Menggunakan Jquery. Yogyakarta. C.V. Andi Offset.

[29] Wardana. 2016. Aplikasi Website Profesional dengan PHP dan jQuery. Jakarta: PT Elex Media Komputindo. 